\title{
Early gonadal maturation and vitellogenin mRNA expression in Siberian sturgeon Acipenser baerii cultured in a semi-closed water recirculating system in Korea
}

\author{
Chulhong Park ${ }^{1}$, Seung Pyo Gong ${ }^{2}$, Youn Hee $\mathrm{Choi}^{2}$, Ki Hong $\mathrm{Kim}^{3}$ and Yoon Kwon Nam ${ }^{2, *}$ \\ ${ }^{1}$ Dinoville Sturgeon Aquafarm, Hamyang 50027, Korea \\ ${ }^{2}$ Department of Marine Bio-Materials \& Aquaculture, Pukyong National University, Busan 48513, Korea \\ ${ }^{3}$ Department of Aquatic Life Medicine, Pukyong National University, Busan 48513, Korea
}

Received August 22, 2020

Revised September 17, 2020

Accepted September 17, 2020

*Correspondence

Yoon Kwon Nam

E-mail: yoonknam@pknu.ac.kr

ORCID

https://orcid.org/0000-0001-8870-2098

\begin{abstract}
Changes of gonadal morphology and mRNA expression patterns of vitellogenin were investigated in Siberian sturgeon Acipenser baerii (Chondrostei) during its early gonadal maturation period. Early differentiations and morphological transitions of both ovaries and testes appeared to occur actively until the age of 3 years, however from then on, the maturation patterns to full maturity were largely gender-dependent, in which males showed a faster progression of maturation than did females while females experienced a steady-state progress with a lagged interval before entering the final maturation. Expression of vitellogenin mRNAs are closely correlated with transitional patterns of gonadal appearances. In both females and males, hepatic mRNA levels of vitellogenin exponentially increased in the earliest interval (up to 1-year-old). However, in subsequent periods, vitellogenin expression in females continued to increase with age, whereas in males, the expression stabilized at a younger age. Nevertheless, at the age older than or equal to 7-year-old, fully matured individuals showed a quite low level of vitellogenin expression in both females and males. Collectively, results from this study could be useful as a fundamental guideline to address the gonad maturation of this sturgeon species, which is helpful for making practical decisions about farming practices and management for caviar production on local sturgeon farms.
\end{abstract}

Keywords: Acipenser baerii, gonad maturation, Siberian sturgeon, vitellogenin expression

\section{INTRODUCTION}

The Siberian sturgeon Acipenser baerii is a critically endangered fish in Acipenseriformes. Owing to increasing demand for the caviar production with this species, Siberian sturgeon has become one of the most popularly aquacultured Acipenser species worldwide (Gisbert and
Ruban, 2003; Doukakis et al., 2012). This sturgeon species was also introduced into the Korean aquaculture domain in the late 1990s, and from then on, early pioneering works on artificial fingerling production (Park et al., 2013a, 2013b) have been followed by a wide spectrum of studies including evolution (Kim et al., 2019a), cell culture (Ryu et al., 2018), anesthesia (Kim and Nam, 2018) 
and innate immunity (Kim et al., 2019b). However, the reproductive performance of farm-bred Siberian sturgeon under local culture conditions in Korea has been little explored, where, hitherto, the investigation on the gonadal maturity based on periodical observations during its reproductive cycle has not been challenged. From aquaculture point of view, one of the most chief concerns of sturgeon farming is to understand how long it will take until caviar production is possible. Because most sturgeon species including $A$. baerii typically have long life spans and achieve reproductive maturity late in life (Birstein et al., 1997; Webb and Doroshov, 2011), the caviar production is generally only possible through continuous farming efforts for many years even under well-controlled culture conditions. Within this context, it is important to validate whether artificially produced sturgeons are maturing normally in the farm environment, and knowing this fact is undoubtedly indispensable in making various decisions about culture practices on farms.

Reproductive biology of $A$. baerii has been previously described (Le Menn et al., 2018; Williot and Chebanov, 2018), however, it has been widely agreed that the reproductive performance of farmed sturgeons could be highly influenced by culture environments, as evidenced by repetitive observations that times to sexual maturity could be significantly variable depending on different regions and countries (Chebanov and Galich, 2011; Williot and Chebanov, 2018). Siberian sturgeon is an exotic fish species to Korea, and the reproductive capability of domestically farm-bred individuals has been insufficiently addressed. Accordingly, guidelines are highly recommended for local farm managers to evaluate the normal maturity progression of Siberian sturgeons being cultured for caviar production.

In accordance with our final goal to figure out the biotic and abiotic factors affecting maturation of Siberian sturgeon farmed in Korea, a long-term observational study was conducted on the gonadal maturation of Acipenser baerii cultured in farm. We quantitatively investigated age-dependent patterns of hepatic vitellogenin mRNA expression levels during early gonadal maturity at 1-year intervals (up to age of 4 years), accompanied with observational assessments of morphological transitions of both ovaries and testes. Vitellogenin expression levels in fully mature, 7- or 8-year-old adult individuals were also measured for comparing vitellogenin mRNA levels between early maturity and full maturity.

\section{MATERIALS AND METHODS}

\section{Sturgeon specimens and culture conditions}

Siberian sturgeon specimens used in this study were farm-bred stocks that had been artificially propagated and maintained in a local farm, Dinoville Sturgeon Aquafarm, Hamyang, Kyoung-nam, South Korea. Induced spawning was conducted by using an intraperitoneal injection of LHRH analogue, and artificial insemination was carried out using wet-method according to descriptions in our previous work (Park et al., 2013a). Egg incubation and larval nursery were also performed following the method described by Park et al. (2013b). Fish were reared at $17-19^{\circ} \mathrm{C}$ until they reached the fingerling size (approximately $10-12 \mathrm{~cm}$ of total length), and afterward, cultured at ambient water temperature. Over the entire period of experiment, the minimum and maximum 'in-tank' water temperatures were $11.4^{\circ} \mathrm{C}$ (recorded in January) and $21.8^{\circ} \mathrm{C}$ (in August). There was no significant difference in the monthly change pattern of water temperature between years. During the grow-out period after fingerling stage, fish were cultured in a semi-closed water recirculating system, in which daily 'in-tank' water recirculation rate was five times during October to February, while six to seven times during March to September. Water exchange rate was $10 \%$ per day in average. Dissolved oxygen (DO) level was adjusted to be ranged within $8.0 \pm 1.5 \mathrm{ppm}$. Subadult and adult fish were fed with commercial diet pellets for rockfish $(50 \%$ of crude protein, Woosung Feed Corp., Daejeon, Korea) with the daily feeding rate of $0.3 \%$ of body weight (BW). Stocking density was $20-30 \mathrm{~kg}$ per 1 ton of in-tank water with periodic adjustments of the density at 4-month intervals. Described experiment was approved by the Animal Care and Use Committee of $\mathrm{Pu}-$ kyong National University (Approval number: 201818).

\section{Observation regimes for gonadal maturity}

Siberian sturgeon individuals were sampled over a period of 7 months to 4 years of age where specific ages in a daily basis were 215 days (7.07 months or 0.59 -yearold), 374 days (1.02-year-old), 731 days (2.00-year-old) and 1,115 days (3.05-year-old) and 1,456 days (3.99-yearold). To minimize seasonal bias for evaluating gonadal maturity, every sampling except for the age of 7 months 
was made in the spawning season (March to April) under the farm conditions. Fish were euthanatized with over dose $(10,000 \mathrm{ppm})$ of clove oil (Sigma-Aldrich, St. Louis, USA), and body weight (BW) and total length (TL) of each individual were measured to the nearest $1.0 \mathrm{~g}$ and 0.1 $\mathrm{cm}$, respectively. Gonads were surgically removed and subjected to phenotypic sexing and maturity assessment. If needed, histological examination was carried out using conventional hematoxylin-eosin staining of $6-\mu \mathrm{m}-$ sectioned gonadal tissue samples. Liver sample was also obtained in order to measure vitellogenin gene expression at each time point of gonad sampling.

\section{RT-qPCR assay of vitellogenin mRNA expression}

Total RNA was extracted from liver samples using Trizol reagent (Thermo Fisher Scientific, Waltham, MA, USA) and further purified using RNeasy Plus Mini-kit (Qiagen, Hilden, Germany) including the DNA removal step according to the manufacturer's recommendations. Integrity of total RNA samples was validated based on the intensity ratio of 28S rRNA and 18S rRNA bands visualized in ethidium-bromide-stained MOPS/formaldehyde $1 \%$ agarose gel. Purity of the total RNA was confirmed by examining absorbance ratios at least higher than 1.9 at both 260/280 nm and 260/230 nm measured with NanoDrop spectrophotometer (ND 1000, Thermo Fisher Scientific). An aliquot of total RNA was reverse transcribed into cDNA using Omniscript RT System (Qiagen) including both oligo-d $(\mathrm{T})_{20}$ and random nonamer primers according to manufacturer's instructions. Synthesized cDNAs were ten-fold diluted with water and $2 \mu \mathrm{L}$ of the diluted cDNA was used as the template for quantitative PCR amplification (qPCR).

For qPCR assay, a pair of oligonucleotide primers (ABVTG-q1F: 5'-ACTACCAAAGGCTCTGTCAG-3' and ABVTG-q1R: 5'-ACCTTGACCTGCACTGTCTT-3') were designed to amplify the 182-bp of internal segment of vitellogenin transcript (GenBank accession number HQ007054.1), while a primer pair (AB-18S-q1F: 5' -ATACAGGACTCTTTCGAGGC-3' and AB-18S-q1R: 5' -CTCAGTTAAGAGCATCGAGG-3') were used to amplify the 248-bp A. baerii 18S rRNA (AY904463.1) (Kim et al., 2019a) segment as a normalization reference. PCR efficiency higher than $90 \%$ was verified for both genes with standard curves prepared with five serially log-diluted cDNA samples. Amplification was conducted for 45 cycles at $95^{\circ} \mathrm{C}$ for $20 \mathrm{~s}, 60^{\circ} \mathrm{C}$ for $20 \mathrm{~s}$ and $72^{\circ} \mathrm{C}$ for $20 \mathrm{~s}$ with an initial denaturation step at $94^{\circ} \mathrm{C}$ for 3 min using $2 X$ SYBR master mix and Light Cycler 480 Real-Time Detection System (Roche Applied Science, Penzberg, Germany). After the final extension step, primer dissociation curves were examined to confirm the specificity of the amplification for both genes. Relative expression levels of hepatic vitellogenin mRNAs across experimental groups were estimated with the $2^{-\mathrm{ACt}}$ method based on the normalization against expression levels of $18 \mathrm{~S}$ rRNA control (Schmittgen and Livak, 2008). Triplicate amplifications were made for each cDNA sample.

\section{Statistics}

Differences in vitellogenin gene expression levels were assessed with one-way ANOVA followed by Duncan's multiple range tests and/or Student's $t$-test at the level of $p<0.05$. Sex ratio examined for each group was assessed with Chi-square test at $p<0.05$.

\section{RESULTS}

Average values of body weight (BW) and total length (TL) of $A$. baerii individuals examined for gonad observation and gene expression assay were indicated in Table 1. For

Table 1. Information on the experimental Acipenser baerii specimens used in gonad observation and vitellogenin mRNA expression assay

\begin{tabular}{clccc}
\hline Age & Gender & $\begin{array}{c}\text { No. of specimens } \\
\text { examined }(\mathbf{n})\end{array}$ & $\begin{array}{c}\text { Body weight } \\
(\mathbf{g})\end{array}$ & $\begin{array}{c}\text { Total length } \\
(\mathbf{c m})\end{array}$ \\
\hline 7 months & Female & 8 & $39.5 \pm 9.6$ & $21.5 \pm 3.1$ \\
& Male & 6 & $40.1 \pm 5.8$ & $20.9 \pm 2.7$ \\
& Unknown & 11 & $36.6 \pm 6.5$ & $21.8 \pm 3.3$ \\
1 year & Female & 14 & $693.5 \pm 135.1$ & $61.5 \pm 6.1$ \\
& Male & 12 & $712.0 \pm 201.2$ & $68.8 \pm 3.9$ \\
2 years & Female & 12 & $1021.8 \pm 192.5$ & $78.5 \pm 4.9$ \\
& Male & 12 & $1321.5 \pm 212.4$ & $80.1 \pm 6.4$ \\
3 years & Female & 13 & $2244.5 \pm 298.5$ & $91.5 \pm 8.9$ \\
& Male & 14 & $2431.7 \pm 321.6$ & $94.4 \pm 7.8$ \\
4 years & Female & 12 & $2833.5 \pm 421.5$ & $104.5 \pm 8.5$ \\
& Male & 13 & $2599.1 \pm 314.2$ & $98.9 \pm 6.6$ \\
7 years & Female & 11 & $5151.6 \pm 522.3$ & $121.4 \pm 11.5$ \\
& Male & 10 & $3521.6 \pm 287.9$ & $115.5 \pm 10.9$ \\
& Intersex & 2 & $3685.0 \pm 316.0$ & $104.7 \pm 14.9$ \\
8 years & Female & 9 & $5322.4 \pm 625.4$ & $136.8 \pm 14.5$ \\
& Male & 7 & $3905.7 \pm 349.6$ & $122.1 \pm 15.5$ \\
\hline
\end{tabular}

Seven-month-old individuals of unknown gender were excluded from RTqPCR analysis. 
each age group, the sex ratio was close to $1: 1$ without significant deviations $(p>0.05)$.

\section{Ovarian appearances during early maturation}

Representative images for ovarian maturation addressed in this study are provided in Fig. 1. At the age of 7 months, the phenotypic sexing with naked eyes is almost impossible with many individuals, and even if examined under microscopy, the gonadal sexes of several fishes was still unclear (not shown). From the external view, the müllerian duct, which is an annex of the ovary, could be identifiable, but any specific sign related to the apparent maturation was not visually observed (Fig. 1A). When fish reached 1-year-old, the differentiation of early ovary was obvious, allowing visual identifications of ovarian fats and oocyte-containing tissues. The oocyte-containing tissue was observed in the form of a white, opaque, lined shape in an undeveloped state. Oocytes were mainly at previtellogenic stage. The ovarian fat tissue appeared as a yellow line structure (Fig. 1B). At the age of 2 years, the lobeshaped ovary was more easily identifiable with unaided eyes along with the ovarian fat tissue. In some parts of ovarian tissues, oocytes that entered early vitellogenic phase were visually distinguishable from one another (Fig. 1C). Three-year-old females showed ovaries with significantly enlarged volumes compared to younger females.
Oocytes in those ovaries represented the vitellogenesis in progress. Owing to increased ovary size, external gonad biopsy without sacrificing the fish may also be possible at this age (Fig. 1D). The ovarian maturity was further signified at the age of 4 years, and the ovarian volumes were also greater compared to those of 3-year-old females, in general. A number of clearly yolk-laden (but still whitecolored) oocytes were easily found in ovarian tissues (Fig. 1E). Notably, at the age of 4 years, we found that there were larger individual variations in ovarian maturation, compared to at younger ages. Many of 4-year-old females examined generally represented a significant advance of maturation from the previous year whereas some others still showed similar appearances with the ovaries of 3-year-old fishes. Even though we did not periodically continue the observational monitoring in subsequent ages, such a non-uniformity in the degrees of ovarian maturation tended to be persistent at ages of 5 and 6 years, based on occasional and non-periodical observations. Thereafter, ovaries containing fully yolk-laden, dark grey colored oocytes with diameters ranging from 2.0-3.0 $\mathrm{mm}$, which corresponds to a typical appearance of Siberian sturgeon caviar, began to be observed from the age of 7 years (Fig. 1F).
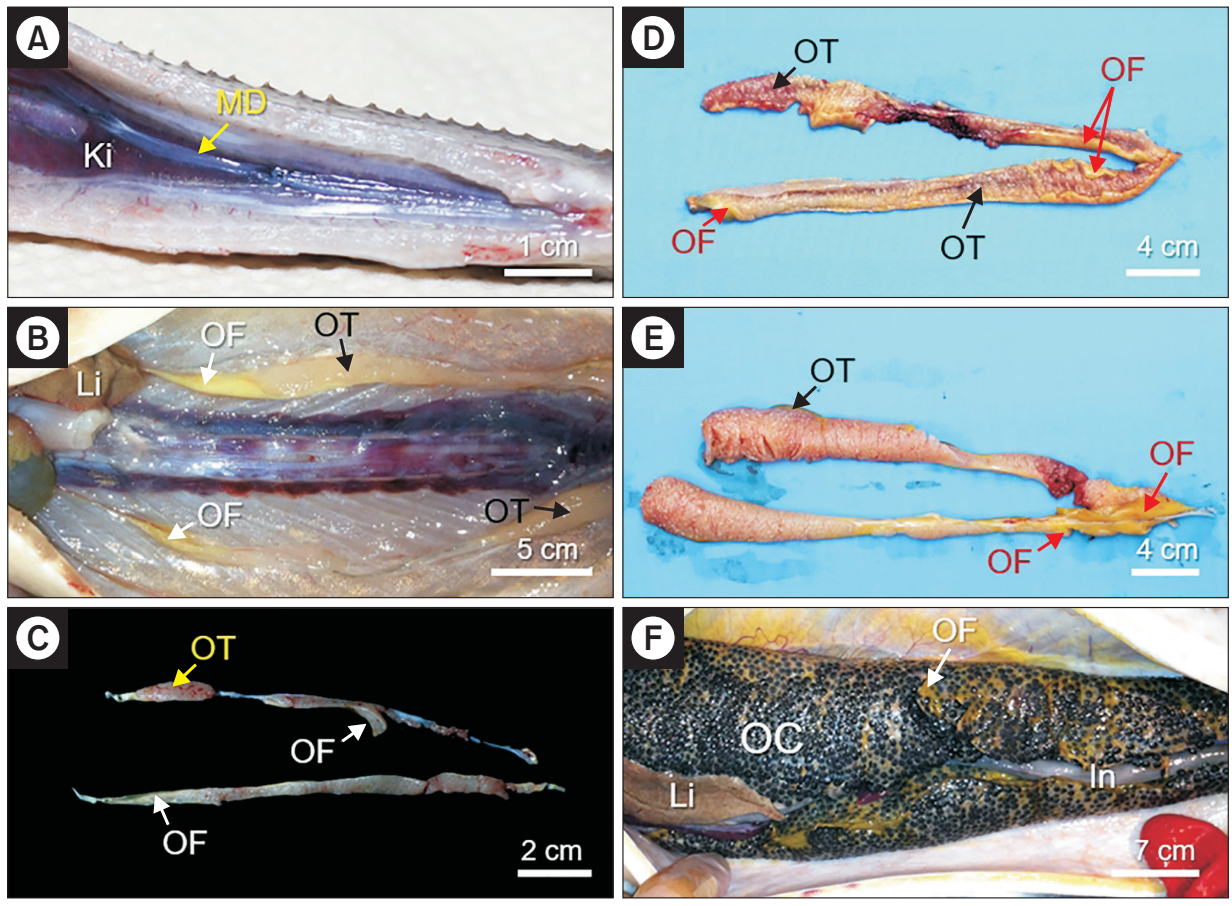

Fig. 1. Representative photographs showing ovarian appearances of $\mathrm{Si}-$ berian sturgeon Acipenser baerii examined in this study at the age of 7 months (A), 1 year (B), 2 years (C), 3 years (D), 4 years (E) and 7 years (F). Abbreviations are müllerian duct (MD), kidney (Ki), liver (Li), ovarian fat (OF), ovarian tissue (OT), intestine (In) and mature oocyte (OC). 


\section{Testicular appearances during early maturation}

Similar with females, testicular development was not clearly visible at the earliest detection point (7-month-old) when assessed with naked eyes, and the maleness is identifiable in some individuals when analyzed with histological techniques (not shown). However, afterward, Siberian sturgeon males exhibited relatively a faster progress of their testicular maturation than did females (Fig. 2). As early as at the age of 1 year, developments of immature testis and Wolffian duct could be identified with naked eyes. In the lobe-shape structure, small and scattered testicular tissues were interconnected with red-yellow fat tissues. However, the relative proportion of testicular tissues in the whole gonadal mass was less than $50 \%$ in most males (Fig. 2A). At the age of 2 years, milky-white colored testes were easily observable in majority of males and the proportion of spermatogenetic testicular tissues relative to fat tissues apparently increased in those males. Even with not all males, external gonad biopsy might be potentially possible (Fig. 2B). When fish reached the age of 3 years, a great deal of changes in the testicular maturity was detected in a number of males, where testicular volumes became notably enlarged and bulky testes in milky white color were evident. Technically, most of those males were easily amenable to the external gonad biopsy-based sex identification (Fig. 2C). Morphological appearances of testes from 4-year-old males were not significantly different from those observed with 3-year-old males. In those males, testicular fats were almost absorbed or was no longer observed (Fig. 2D). Subsequently, the external appearance of testis was not fundamentally changed till the end of our observational study, although older males usually tended to exhibit increased testicular volumes (Fig. 2E). Meanwhile, at the age of 7 years, we found two hermaphroditic individuals representing intersex gonads containing both ovarian and testicular tissues together (Fig. 2F).

\section{Age-dependent vitellogenin mRNA levels}

As shown in the Fig. 3, 7-month-old individuals represented a very negligible level of hepatic vitellogenin expression. However, vitellogenin expression was significantly upregulated in subsequent studied period in an age-dependent manner $\left(\mathrm{R}^{2}>0.90\right.$ for both sexes). Mean expression level of vitellogenin mRNAs in 1-yearold females was more than 1,500 -fold relative to that of 7-month-old individuals. During the age interval from 1 to 3 years, hepatic vitellogenin mRNA levels in females continued to increase with age, consequently resulting in
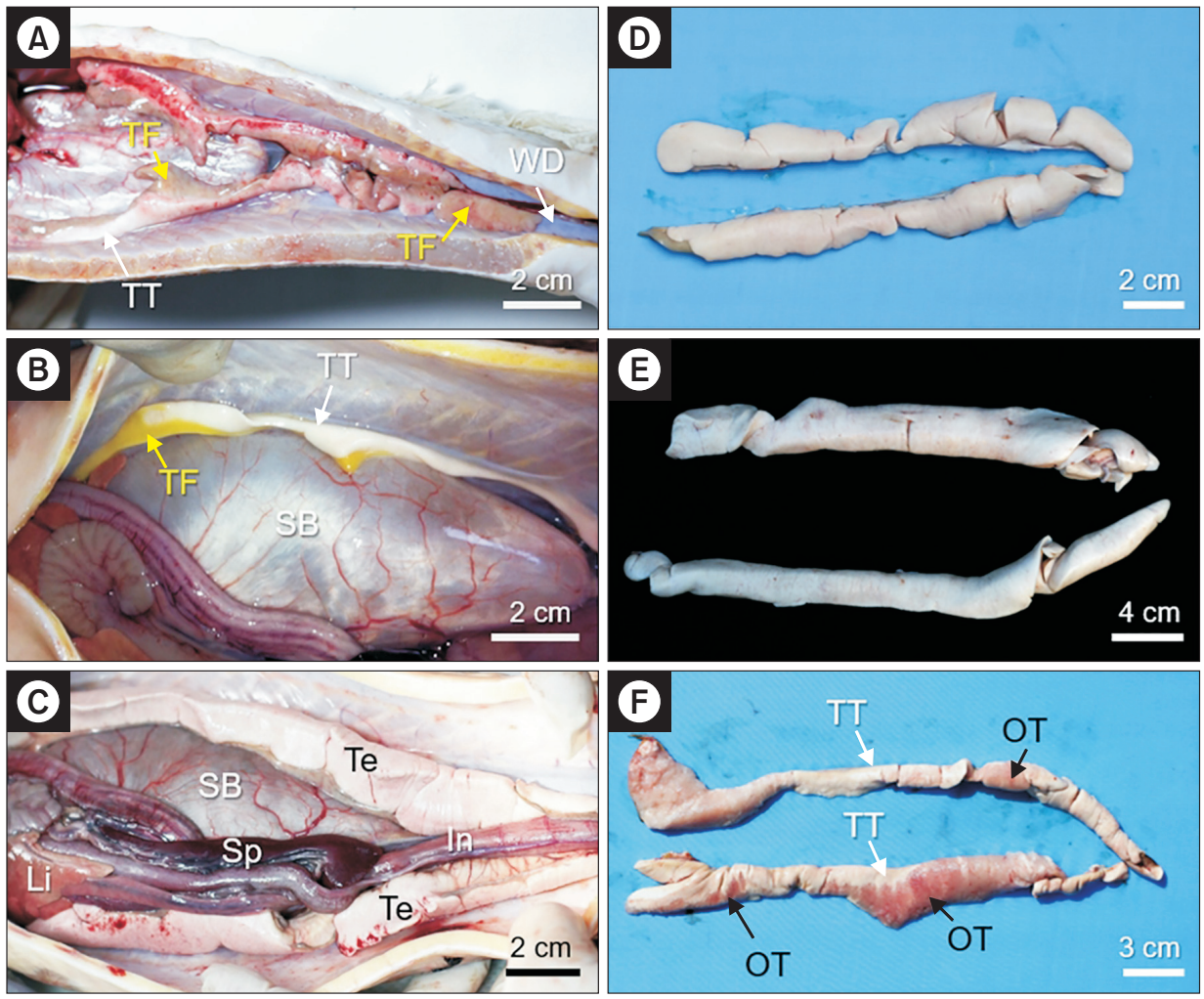

Fig. 2. Representative photographs showing testicular appearances of Siberian sturgeon Acipenser baerii examined in this study at the age of 1 year (A), 2 years (B), 3 years (C), 4 years (D) and 7 years (E). The hermaphroditic intersex gonad simultaneously containing both testicular and ovarian tissues from a 7-year-old fish is also shown in (F). Abbreviations are Wolffian duct (WD), testicular fat (TF), testicular tissue (TT), swim bladder $(\mathrm{SB})$, liver (Li), spleen (Sp), intestine $(\mathrm{In})$, ovarian tissue (OT) and mature testis (Te). 
A

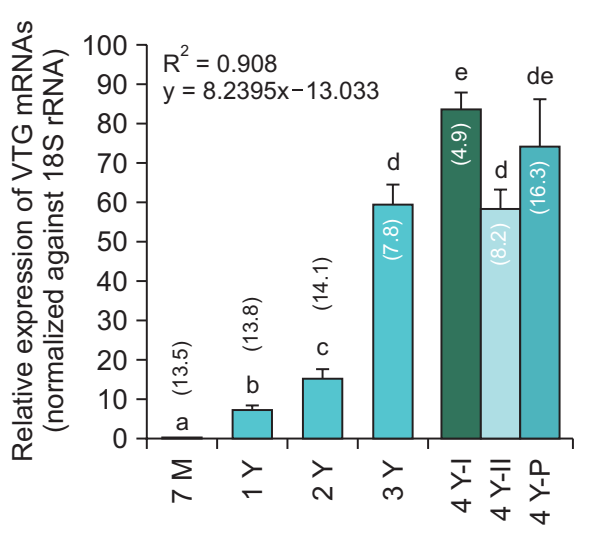

Age groups
B

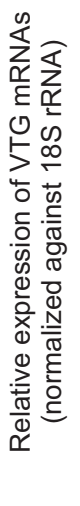

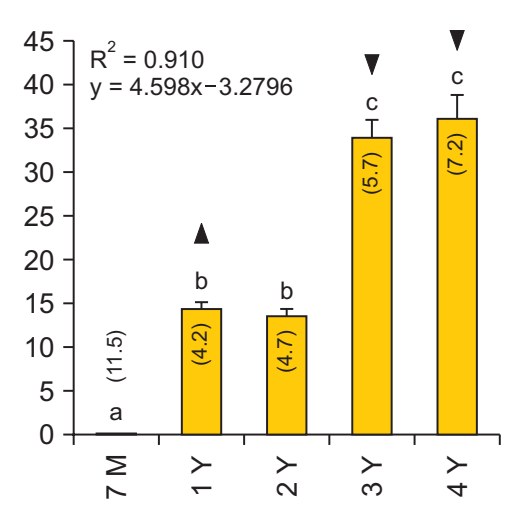

Age groups
C

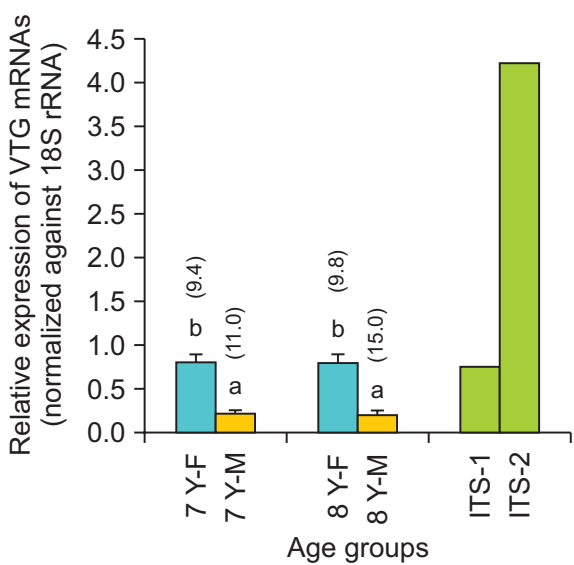

Fig. 3. Age-dependent hepatic mRNA expression levels of vitellogenin (VTG) gene in Siberian sturgeon Acipenser baerii as determined by RT-qPCR assay. (A) Vitellogenin expression levels in females sampled over a period of 7 months (7M) to 4 years (4Y) of age. At the age of 4 years, the average expression level in females showing the apparent advance of ovarian maturation from the appearance in the $3 Y$-individuals is labeled as $4 Y-I$, while the expression level in $4 Y$-females exhibiting only similar ovarian appearance with $3 \mathrm{Y}$-fish is indicated as $4 \mathrm{Y}-\mathrm{II}$. The label $4 \mathrm{Y}-\mathrm{P}$ indicates the average with pooled data without distinguishing $4 \mathrm{Y}-\mathrm{I}$ from $4 \mathrm{Y}-\mathrm{II}$. Means with different letters are significantly different based on ANOVA followed by Duncan's multiple range tests at $p<0.05$. Numbers in parentheses are percent coefficient of variation values. The coefficient of determination $\left(R^{2}\right)$ and the corresponding equation are also provided on the upper left of the graph. (B) Expression levels in males. Regimes for labeling and statistic evaluation are same as in (A). Additionally, the closed triangle indicates the significantly higher level of vitellogenin mRNA expression in males compared to that in same-aged females, based on Student's t-test $(p<0.05)$. On the other hand, the significantly lower expression level in males compared to that in females is indicated by inverted closed triangle $(p<0.05)$. (C) Expression levels in fully matured females and males at ages of 7 and 8 years (7Y-F and $8 Y-F$ for females while $7 Y-M$ and $8 Y-M$ for males). Individual expression levels of two hermaphroditic intersex fish (ITS-1 and ITS-2; 7-year-old) are also presented.

the mean expression level at the age of 3 years was 3.8fold and 8.1-fold relative to those at 2 years and 1 year, respectively $(p<0.05)$. At the age of 4 years, many females showed a further increase of vitellogenin mRNA levels ( $p$ $<0.05)$ whereas some others represented no assignable increase in vitellogenin expression levels from the age of 3 years $(p>0.05)$. Such discrepancies came from different degrees of ovarian maturity between the two expression groups, although such a close relationship between ovarian maturity and vitellogenin expression level doesn't always fit exactly in all the 4-year-old females (Fig. 3A).

Males also showed a sharp and exponential increase of vitellogenin expression during the interval from 7 months to 1 year of age (more than 2400 times increased from the basal level at 7 months). Notably, the average vitellogenin mRNA level in 1-year-old males was even higher than that in same-aged females $(p<0.05)$. However, males did not show any assignable changes of the vitellogenin expression during the period from 1 year to 2 years $(p>0.05)$. At the age of 3 years, vitellogenin mRNA levels increased from the previous year $(p<0.05)$, but no more increase was found at the age of 4 years ( $p>0.05)$ (Fig. 3B).
In contrast to substantial increases during early gonadal maturity, fully matured Siberian sturgeons represented significantly low levels of vitellogenin mRNAs. Even though vitellogenin expression levels in females at full maturity were higher than those in fully matured males, the mean expression levels in 7- or 8-year-old females were only about $1 \%$ of that measured with 4 -year-old females. As similar, the 7- or 8-year-old mature males represented the mean expression levels that accounted for only $0.6 \%$ of that expressed in 4 -year-old males. On the other hand, the two exceptional hermaphroditic individuals (both 7-year-old) showed significantly different expression levels one another: one intersex fish showed a significantly higher expression than those measured with normal females and males, while the other exhibited a similar level with that observed with same-aged normal females (Fig. 3C).

\section{DISCUSSION}

Early sex identification is important in the culture of fish species exhibiting sex-related dimorphism in eco- 
nomic traits. Because the commercial culture of sturgeons is usually aimed to produce caviar, the achievement of all-femaleness in culture stocks might have been a matter of long agony in sturgeon aquaculture industries. However, despite a lot of efforts in the past, the highly effective DNA markers capable of genetic sexing has not been developed yet in Acipenser species (Keyvanshokooh and Gharaei, 2010; Simide and Gaillard, 2018). Alternatively, several instrumental technologies including the reading of ultrasound image have been being developed as a noninvasive means for gonadal sexing (Chebanov and Galich, 2011; Memiş et al., 2016), however, its applicability is still limited to substantially mature individuals. For this reason, the most common and practical method in many sturgeon farms has still relied on the direct examination of a small piece of gonad sample through the skill called micro-surgery-based external gonad biopsy (Chapman and Park, 2005; Webb et al., 2019). With this viewpoint, it is therefore important to know the minimum age at which the external gonad biopsy can be effectively applied to both sexes. From our observational data, we recommend that the external gonad biopsy is practically applicable to most males and females at age of 3 years, if they are grown under similar culture conditions from those described in this study. When considering the sacrifice of the fish, the visual verification of phenotypic sex is virtually possible at the age of 1 year even though earlier identification might also be achieved by using the gonad histology.

Under present culture conditions, Siberian sturgeon females display significant changes in their ovarian appearances during early life period up to 3 years, however, subsequently, the maturation of oocytes seems to be executed at relatively a steady-state and slow rate until the final maturation is triggered around the age of 7 years. During this steady-state period, sexually differentiated but immature females might invest or allocate their energy to both growth and gonad maturation (McBride et al., 2015). Our finding on noticeable variations in maturity among 4-year-old females may be in relation to individualdependent energy allocation strategies to egg maturation. Although we did not conduct detail monitoring in subsequent ages due to such large individual variations, we found that the oocyte growth in this phase seemed to be notably slow and even suspected to be almost halted. Only after reaching the age of 7 years, oocyte maturation is somewhat accelerated and such that 'caviar-like' oocytes are found in considerable numbers of females, implying that a certain biological signaling is essentially needed to trigger oocytes to enter the final maturation stage (Nagahama and Yamashita, 2008; Samarin et al., 2019). Unlike ovarian maturation, the process of testicular maturation was achieved relatively earlier without a lag interval intercepted between the initial and final maturation stages. Siberian sturgeon males in this study is potentially capable of the final maturation of male gametes at the age of 4 years. Although not all those males were tested, several 4-year-old males subjected to induced hormonal spermiation trials were proven to be able to provide a good quality of sperm that can be highly compatible with artificial insemination trials (data not shown), suggesting that, at least in a certain portion of males, the process of not only spermatogenesis but also functional spermiogenesis could be completed by this age (Schulz et al., 2010; Dzyuba et al., 2017; Grandi et al., 2018).

From the vitellogenin gene expression assay, the expression was modulated toward upregulation during early gonadal maturity. It is similar with the elevated vitellogenin expression in accordance with either gonadal development or reproductive cycle, which has been observed not only in this chondrostean fish group but in other teleost species (Amberg et al., 2010; Zhang et al., 2011a; Hara et al., 2016; Fajkowska et al., 2016). In early works, vitellogenin has been originally thought as a mature female-specific protein since it is the main proteinogenic component of fish yolk, however, a number of subsequent studies have indicated that the transcription of vitellogenin gene is active also in both males and sexually immature fishes (Arukwe and Goks øyr, 2003; Zhang et al., 2005; Reading et al., 2018). Similarly, in this study, Siberian sturgeon males robustly display hepatic vitellogenin transcripts of which expression levels are readily comparable to those observed in females or even higher than in females in a certain life interval. Congruent with previous reports, vitellogenin, as a member of large lipid transfer protein, should play important roles in not only the accumulation of yolks in ovary but also other 'genderindependent' metabolic pathways in this chondrostean fishes. Noticeably, several previous studies have proposed that the regulation of vitellogenin expression would be closely intertwined with the innate immune response in teleosts (Tong et al., 2010; Zhang et al., 2011b; Sun and 
Zhang, 2015).

Nevertheless, our RT-qPCR data have indicated that the gonadal maturation is a principal factor that modulates vitellogenin gene expression in males as well as females. The significant fold change of the vitellogenin expression in the earliest interval until the age of 1 year may reflect the increasing demand of vitellogenin for preparing the initiation of gamete growth and the formation of early gonads in both sexes. The fact that both ovary and testis of this sturgeon species have been known to accumulate large amounts of lipids during this period is in agreement with our RT-qPCR data (Ma et al., 2011; Zhu et al., 2020). After this initial elevation, the modulatory pattern of vitellogenin expression would be gender-dependent in subsequent intervals, which is also closely in relation with yearly changes of ovarian and testicular morphologies. In overall, females represented a continuous increase of vitellogenin expression levels with ages up to 4 years, while the expression in males reached plateau at 3 years and no more increased subsequently. Such discrepancies may be in relation to the gender-dependent demand of vitellogenin for preparing the final version of gametes (i.e., highly yolk-laden eggs vs. spermatozoa almost lacking cytoplasmic contents). Within this point of view, the significant upregulation of vitellogenin expression at the age of 3 years may reflect the increasing demand of vitellogenins to meet the active growth of gametes in enlarged gonad volumes. Also, no additional increase of the expression in males during the period from 3 years to 4 years of age is in congruent with that there is no significant or fundamental transition in testicular morphologies between 3-year-old and 4-year-old males.

However, when fish reach the full maturity of gonads, the vitellogenin expression was significantly downregulated in both females and males. Expression levels in 7 - or 8 -year-old females were equivalent to only $1 \%$ of those measured with 4-year-old age females, suggesting that active transcription of vitellogenin gene is no longer needed for the post-vitellogenic process to attain at the final oocyte maturation. Proteolytic vitellogenic substances are long-lasting molecules in oviparous fish eggs since those biomolecules should be stably delivered to embryos and early larvae (Zhang et al., 2011a; Salmela et al., 2015). However, one unexpected finding is the fact that such a striking downregulation at full maturity is similarly observed also in males, suggesting that the last step of spermiogenesis in aged $A$. baerii males may happen in parallel with the negative regulation of hepatic vitellogenin genes, although much extensive investigations on modulation mechanism(s) of vitellogenin gene expression should be needed at finer age intervals after the early gonad maturation. Meanwhile, we found two exceptional individuals showing the hermaphroditism in their gonads. Occurrence of intersex gonads in farmed and captive sturgeons have been reported in Acipenser species (Jackson et al., 2006; Matsche et al., 2013; Rzepkowska et al., 2014), although the causative factor has not been yet clearly elucidated in detail. The two hermaphroditic fish examined in this study showed very different levels of vitellogenin expression, which may be related to differences in maturity and mixed composition ratios of ovarian and testicular tissues. Although we did not quantitatively analyze the composition ratio in detail, the intersex fish showing the higher vitellogenin expression (ITS-2 in Fig. 3C) exhibited relatively a larger proportion of ovarian tissue in its hermaphroditic gonad (shown in Fig. 2F), when compared to the other fish (ITS-1) of which gonad was almost occupied with testicular tissues and only a very small portion of immature ovarian tissue was observable in a restricted area (not shown). Considering that the maturation stage of ovarian tissues existing in those intersex gonads would roughly corresponded to the early vitellogenic stage, the reason responsible for differential levels of vitellogenin expression between the two individuals could be, at least in part, related to different composition ratios of ovarian tissues. However, due to the limited number, it is currently difficult to develop a generalized interpretation on the interrelationship between intersex phenotypes and vitellogenin expression patterns. Further examination with larger number of intersex specimens is needed to better solidify our current explanation.

In summary, hepatic vitellogenin gene expression was investigated along with observational analysis of gonadal appearances in Siberian sturgeon $A$. baerii during its early life periods. Under local culture conditions described herein, the formation and early differentiation of ovarian and testicular tissues appeared to be actively progressed until the first three years after hatching, however from then on, gender-dependent discrepancies became signified in subsequent studied period. Expression patterns of vitellogenin mRNAs are closely correlated with the progress of early gonad maturation in both genders. In 
overall, the vitellogenin expression in females continued to increase with age up to 4 years, whereas in males, the expression reached maximum at younger age (3 years) and then stabilized. However, at full maturity (older than or equal to 7-year-old), vitellogenin expression levels in aged broodfish fell down to quite low levels in both sexes. Data from this study could be a fundamental reference guideline to address the early gonadal maturity of Siberian sturgeon under local farm conditions, which is useful not only for research investigations on gonad maturation but also for making decisions about farming practices for caviar production.

\section{CONFLICTS OF INTEREST}

No potential conflict of interest relevant to this article was reported.

\section{ACKNOWLEDGEMENTS}

This research was supported by Pukyong National University Development Project Research Fund, 2020.

\section{AUTHOR CONTRIBUTIONS}

CP carried out culture and observational analysis of gonads. SPG co-evaluated the data and co-drafted manuscript. YHC conducted interpretation of gonad maturation and evaluate the phenotypic data. KHK evaluated the gene expression data. YKN designed this study and drafted the manuscript. All authors read and approved the final manuscript.

\section{AUTHOR'S POSITION AND ORCID NO.}

$$
\begin{aligned}
& \text { C Park, Chief Executive Officer, } \\
& \text { https://orcid.org/0000-0003-3589-9864 } \\
& \text { SP Gong, Professor, } \\
& \text { https://orcid.org/0000-0002-9358-9568 } \\
& \text { YH Choi, Professor, } \\
& \text { https://orcid.org/0000-0002-0091-7893 } \\
& \text { KH Kim, Professor, } \\
& \text { https://orcid.org/0000-0002-1140-8162 } \\
& \text { YK Nam, Professor, } \\
& \text { https://orcid.org/0000-0001-8870-2098 }
\end{aligned}
$$

\section{REFERENCES}

Amberg JJ, Goforth R, Stefanavage T, Sepúlveda MS. 2010. Sexually dimorphic gene expression in the gonad and liver of shovelnose sturgeon (Scaphirhynchus platorynchus). Fish Physiol. Biochem. 36:923-932.

Arukwe A and Goksøyr A. 2003. Eggshell and egg yolk proteins in fish: hepatic proteins for the next generation: oogenetic, population, and evolutionary implications of endocrine disruption. Comp. Hepatol. 2:4

Birstein VJ, Hanner R, DeSalle R. 1997. Phylogeny of the Acipenseriformes: cytogenetic and molecular approaches. Environ. Biol. Fishes 48:127-155.

Chapman FA and Park C. 2005. Comparison of sutures used for wound closure in sturgeon following a gonad biopsy. N. Am. J. Aquac. 67:98-101.

Chebanov MS and Galich EV. 2011. Sturgeon hatchery manual. FAO, Ankara, pp. 37-134.

Doukakis P, Pikitch EK, Rothschild A, DeSalle R, Amato G, Kolokotronis SO. 2012. Testing the effectiveness of an international conservation agreement: marketplace forensics and CITES caviar trade regulation. PLoS One 7:e40907.

Dzyuba B, Cosson J, Dzyuba V, Fedorov P, Bondarenko O, Rodina M, Linhart O, Shelton WL, Boryshpolets S. 2017. Sperm maturation in sturgeon (Actinopterygii, Acipenseriformes): a review. Theriogenology 97:134-138.

Fajkowska M, Rzepkowska M, Adamek D, Ostaszewska T, Szczepkowski M. 2016. Expression of dmrtl and vtg genes during gonad formation, differentiation and early maturation in cultured Russian sturgeon Acipenser gueldenstaedtii. J. Fish Biol. 89:1441-1449.

Gisbert E and Ruban GI. 2003. Ontogenetic behavior of Siberian sturgeon, Acipenser baerii: a synthesis between laboratory tests and field data. Environ. Biol. Fishes 67:311-319.

Grandi G, Astolfi G, Chicca M, Pezzi M. 2018. Ultrastructural investigations on spermatogenesis and spermatozoan morphology in the endangered Adriatic sturgeon, Acipenser naccarii (Chondrostei, Acipenseriformes). J. Morphol. 279:1376-1396.

Hara A, Hiramatsu N, Fujita T. 2016. Vitellogenesis and choriogenesis in fishes. Fish. Sci. 82:187-202.

Jackson K, Hurvitz A, Din SY, Goldberg D, Pearlson O, Degani G, Levavi-Sivan B. 2006. Anatomical, hormonal and histological descriptions of captive Russian sturgeon (Acipenser gueldenstaedtii) with intersex gonads. Gen. Comp. Endocrinol. 148:359-367.

Keyvanshokooh S and Gharaei A. 2010. A review of sex determination and searches for sex-specific markers in sturgeon. Aquac. Res. 41:el-e7.

Kim CH, Kim EJ, Nam YK. 2019a. Chondrostean sturgeon hepcidin: an evolutionary link between teleost and tetrapod hepcidins. Fish Shellfish Immunol. 88:117-125.

Kim CH, Kim EJ, Nam YK. 2019b. Subfunctionalization and evolution of liver-expressed antimicrobial peptide 2 (LEAP2) 
isoform genes in Siberian sturgeon (Acipenser baerii), a primitive chondrostean fish species. Fish Shellfish Immunol. 93:161-173.

Kim EJ and Nam YK. 2018. Anesthetic protocol for microinjection-related handling of Siberian sturgeon (Acipenser baerii; Acipenseriformes) prolarvae. PLoS One 13:e0209928.

Le Menn F, Benneteau-Pelissero C, Le Menn R. 2018. An updated version of histological and ultrastructural studies of oogenesis in the Siberian sturgeon Acipenser baerii. In: Williot P, Nonnotte G, Vizziano-Cantonnet D, Chebanov M (Eds.), The Siberian Sturgeon (Acipenser baerii, Brandt, 1869, vol 1, Springer, Cham, pp. 279-305.

Ma J, Zhang T, Zhuang P, Yan SW, Zhang LZ, Tian MP, Gao LJ. 2011. The role of lipase in blood lipoprotein metabolism and accumulation of lipids in oocytes of the Siberian sturgeon Acipenser baerii during maturation. J. Appl. Ichthyol. 27:246-250.

Matsche MA, Rosemary KM, Brundage HM III, O'Herron JC II. 2013. Reproductive demographics, intersex, and altered hormone levels in shortnose sturgeon, Acipenser brevirostrum, from Delaware River, USA. J. Appl. Ichthyol. 29:299-309.

McBride RS, Somarakis S, Fitzhugh GR, Albert A, Yaragina NA, Wuenschel MJ, Alonso-Fernández A, Basilone G. 2015. Energy acquisition and allocation to egg production in relation to fish reproductive strategies. Fish Fish. 16:23-57.

Memiş D, Yamaner G, Tosun DD, Eryalçin KM, Chebanov M, Galich E. 2016. Determination of sex and gonad maturity in sturgeon (Acipenser gueldenstaedtii) using ultrasound technique. J. Appl. Aquac. 28:252-259.

Nagahama Y and Yamashita M. 2008. Regulation of oocyte maturation in fish. Dev. Growth Differ. 2008;50 Suppl 1:S195S219.

Park C, Lee SY, Kim DS, Nam YK. 2013a. Embryonic development of Siberian sturgeon Acipenser baerii under hatchery conditions: an image guide with embryological descriptions. Fish. Aquat. Sci. 16:15-23.

Park C, Lee SY, Kim DS, Nam YK. 2013b. Effects of incubation temperature on egg development, hatching and pigment plug evacuation in farmed Siberian sturgeon Acipenser baerii. Fish. Aquat. Sci. 16:25-34.

Reading BJ, Andersen LK, Ryu YW, Mushirobira Y, Todo T, Hiramatsu N. 2018. Oogenesis and egg quality in finfish: yolk formation and other factors influencing female fertility. Fishes 3:45.

Ryu JH, Kim MS, Kang JH, Kim DH, Nam YK, Gong SP. 2018. Derivation of the clonal-cell lines from Siberian sturgeon (Acipenser baerii) head-kidney cell lines and its applicability to foreign gene expression and virus culture. J. Fish Biol. 92:1273-1289.

Rzepkowska M, Ostaszewska T, Gibala M, Roszko ML. 2014. Intersex gonad differentiation in cultured Russian (Acipenser gueldenstaedtii) and Siberian (Acipenser baerii) sturgeon. Biol. Reprod. 90:31.
Salmela H, Amdam GV, Freitak D. 2015. Transfer of immunity from mother to offspring is mediated via egg-yolk protein vitellogenin. PLoS Pathog. 11:e1005015.

Samarin AM, Samarin AM, Policar T. 2019. Cellular and molecular changes associated with fish oocyte ageing. Rev. Aquacult. 11:619-630.

Schmittgen TD and Livak KJ. 2008. Analyzing real-time PCR data by the comparative $\mathrm{C}(\mathrm{T})$ method. Nat. Protoc. 3:11011108.

Schulz RW, de França LR, Lareyre JJ, Le Gac F, Chiarini-Garcia H, Nobrega RH, Miura T. 2010. Spermatogenesis in fish. Gen. Comp. Endocrinol. 165:390-411.

Simide R and Gaillard S. 2018. Evolution of molecular investigations on sturgeon sex determination and most recent developments in DNA methylation with a focus on the Siberian sturgeon. In: Williot P, Nonnotte G, Vizziano-Cantonnet D, Chebanov M (Eds.), The Siberian Sturgeon (Acipenser baerii, Brandt, 1869), vol 1, Springer, Cham, pp. 71-91.

Sun C and Zhang S. 2015. Immune-relevant and antioxidant activities of vitellogenin and yolk proteins in fish. Nutrients 7:8818-8829.

Tong Z, Li L, Pawar R, Zhang S. 2010. Vitellogenin is an acute phase protein with bacterial-binding and inhibiting activities. Immunobiology 215:898-902.

Webb MAH and Doroshov SI. 2011. Importance of environmental endocrinology in fisheries management and aquaculture of sturgeons. Gen. Comp. Endocrinol. 170:313-321.

Webb MAH, Van Eenennaam JP, Crossman JA, Chapman FA. 2019. A practical guide for assigning sex and stage of maturity in sturgeons and paddlefish. J. Appl. Ichthyol. 35;169186.

Williot P and Chebanov M. 2018. Reproductive cycles in sturgeons with a special focus on the farmed Siberian sturgeon. In: Williot P, Nonnotte G, Chebanov M (Eds.), The Siberian Sturgeon (Acipenser baerii, Brandt, 1869), vol 2, Springer, Cham, pp. 3-12.

Zhang S, Wang S, Li H, Li L. 2011b. Vitellogenin, a multivalent sensor and an antimicrobial effector. Int. J. Biochem. Cell Biol. 43:303-305.

Zhang Y, Qu Q, Sun D, Liu X, Suo L, Zhang Y. 2011a. Vitellogenin in Amur sturgeon (Acipenser schrenckii): induction, purification and changes during the reproductive cycle. J. Appl. Ichthyol. 27:660-665.

Zhang Z, Hu J, An W, Jin F, An L, Tao S, Chen J. 2005. Induction of vitellogenin mRNA in juvenile Chinese sturgeon (Acipenser sinensis Gray) treated with 17beta-estradiol and 4-nonylphenol. Environ. Toxicol. Chem. 24:1944-1950.

Zhu Y, Wu J, Leng X, Du H, Wu J, He S, Luo J, Liang X, Liu H, Wei Q, Tan Q. 2020. Metabolomics and gene expressions revealed the metabolic changes of lipid and amino acids and the related energetic mechanism in response to ovary development of Chinese sturgeon (Acipenser sinensis). PLoS One 15:e0235043. 